\title{
How to exorcise the hazardous effects of ionizing rayst hat are capable to trespass the holes of the ozone layer and provoke serious damages to DNA of epythelial cells
}

\author{
Piotr Brzeziński ${ }^{1}$, Lorenzo Martini²
}

\author{
${ }^{1}$ Interuniversity Centre for researches Advanced Medical Systems, University of Siena, Siena, Italy, ${ }^{2}$ Department of \\ Excellence of Biotechnologies, Pharmacy and Chemistry, University of Siena, Siena, Italy
}

Corresponding author: Prof. Lorenzo Martini, E-mail: martini174@virgilio.it

\begin{abstract}
Ozone layer measurement began in 1956 and its progressive and inexorable depletion has been measured from 1956, cause of the anthropogenic emissions of chlorofluorocarbons of sprays and all the devices apt to refrigeration. The United Nations in 1958 issued a report "Paceful uses of atomic energy" Gévève, 1958 where in Voll.8, 9,10,11,12,22, $23,24,25,26,28$ and 29 it is possible to notice that radiations characterized by high wavelength and low frequence are capable to trespass the ozone layer where "holes" are macroscopic. In this paper the AA have decided to refer all the kinds of biological transformations that can occur in human body owing to the ionizing radiations that trespass the holes of the ozone layers. The dosage of emission of $\gamma$-rays is measured in Sievert or in rem and in the article the AA report the yearly dosage Man was exposed before 1956 and the dosage of emission of the same rays nowadays, and this value is very impressive. The AA have created a cosmetic formula apt to protect skin from absorption of ionizing rays and experimented this lotion onto 10 volunteers who live close to an abandoned nuclear power plant in Campania (IT) where thousands of kilograms of radioactive waste are stowed. After ten days of application of the aforesaid lotion, it is possible to notice that after ten days all the volunteers show a suggestive decrement of various symptoms evoked by exposures to light dosages of ionizing rays (dryness of the mouth and difficulty of swallowing).
\end{abstract}

Key words: Ozone layer; $\gamma$-rays; Malachite extract; Tanacetum annuum flower oil; Sievert; Rem

\section{INTRODUCTION}

In 1956, the British Antarctic Survey set up the Halley Bay Observatory on Antarctica in preparation for the International Geophysical Year (IGY) of 1957. In that year, ozone measurements using a Dobson Spectrophotometer began.

And thus, the ozone layer health status and its progressive and inexorable depletion has been measuring from 1956, cause of the anthropogenic emissions of chlorofluorocarbons of sprays and all the devices apt to refrigeration [1-3].

The United Nations in 1958 issued a report "Paceful uses of atomic energy" Gévève, 1958 where in Voll.8,9,
$10,11,12,22,23,24,25,26,28$ and 29 it is possible to notice that radiations characterized by high wavelength and low frequence are capable to trespass the ozone layer where "holes" are macroscopic.

These kinds of radiations may be subatomic particles, endowed by electric charge, as protons, radiations alpha and beta, non-corpuscular ones, idest electromagnetic waves as $\mathrm{X}$ and $\gamma$ rays $[4,5]$.

Gamma-rays are the most energetic form of light and are produced by the hottest regions of the universe. They are also produced by such violent events as supernova explosions or the destruction of atoms, and by less dramatic events, such as the decay of radioactive material in space. Things like supernova explosions

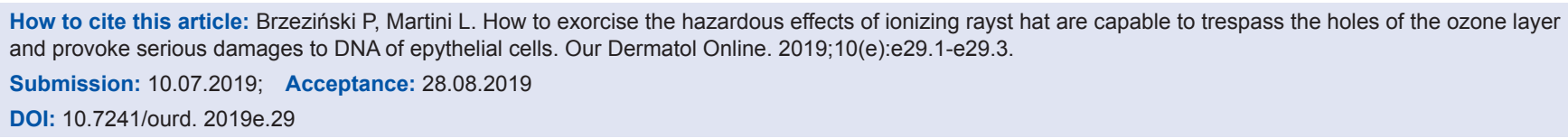


(the way massive stars die), neutron stars and pulsars, and black holes are all sources of celestial gamma-rays.

In Voll 24 and 25 of the document drafted by the United Nations is possible to observe the cascade of interactions between the ionizing rays (e-) and the biologic molecules of the human organism and the possible fates occurring after the intercourse between the e- and the free radicals of the biologic molecules of the human organism after been struck by the same e-.

Here it is noticeable the fate of dimeric, trimeric and tetrameric proteins when struck by a e-:

$\mathrm{AB}+\mathrm{e}-=\mathrm{A}+\mathrm{B}-$

$\mathrm{AAB}+\mathrm{e}-=+\mathrm{AAB}+\mathrm{AAB}-$

$\mathrm{CAAA}+\mathrm{e}-=+\mathrm{CAAA}$

Here one can observe what may happen when charged ions interact with other normal ions, and the possibilities of transformations can be three:

Interatomic: $\mathrm{A}++\mathrm{C}=\mathrm{A}+\mathrm{C}+$

Intramolecular: $+\mathrm{AC}=\mathrm{AC}+$; $-\mathrm{BD}=\mathrm{BD}$ -

Intermolecular: $+\mathrm{AB}+\mathrm{CD}=\mathrm{AB}++\mathrm{CD} ; \mathrm{AB}-+\mathrm{CD}$ $=\mathrm{AB}+\mathrm{CD}-$

And finally two examples regarding what it may happen when a charged molecule may dissociate owing to the ionizing radiations and the metabolites that can produce:

$+\mathrm{ABA}=+\mathrm{A}+\mathrm{BA}^{\circ}\left(\right.$ e.g.: $\left.+\mathrm{H} 20=+\mathrm{H}+\mathrm{OH}^{\circ}\right)$

$+\mathrm{CH} 4=+\mathrm{CH} 4=+\mathrm{C}+2 \mathrm{H} 2$

All these biological metamorphosis represent the apocalyptic aspect of the eventual hazardous destinies the human DNA of the epithelial cells can encounter.

The AA have looked for all the organic or natural substances apt to protect skin and mucosae from the assault of the ionizing rays reaching the environment through the holes of the ozone layer.

Metals that have high atomic number, atomic weight and a specific gravity greater than 5.0 , as noble metals like gold, platinum, ruthenium, rhodium, silver, hyridion could be perfect, but many of these are not admitted in INCI.

Even refractory metals as tungsten and tantalum could be exceptional for this purpose, but all these metals are too much expensive, and forbidden in INCI too.
For this reason the AA have ideated a formula that comprehends gold and copper, and exactly gold zeolite micronized and copper PCA (Pyrrolidon carboxylic acid).

Dosages can be very low (10 ppm): it is not necessary to exceed with the percentages.

In Nature other ingredients exist that can be useful in this case, and may be used in very low percentages: Malachite extract (10ppm)

Tanacetum annuum flower oil $(10 \mu \mathrm{g} / \mathrm{ml})$

Clitoria ternatea flower extract(butterfly pea) $(100 \mu \mathrm{g} / \mathrm{ml})$

Urtica dioica extract (nettle) $(150 \mu \mathrm{g} / \mathrm{ml})$.

The formula comprises all these ingredients and is dispersed in liquid talc.

Now, when DNA of the epithelial cells is broken by $\gamma$-rays or X-rays, the nucleotide, if not exposed anymore to the same radiations, is capable to repair the damaged molecules, in a determined time.

Rothkamm e Lobrich [6] referred that the repairing ability of the nucleotides is faster when the exposition to $\gamma$-rays is prolonged and at highest dosages, meanwhile this ability is slower and more difficult when exposure to $\gamma$-rays is shorter and at lower dosages.

When the ozone layer was inviolate (before World War II) and in 50s, the yearly exposure of Man to $\gamma$-rays was $10-20$ rem (1-2 mSievert), nowadays the exposure is 30-60 rem (3-6 mSievert), because of the holes of the ozone layer.

We have to consider that the dosage emitted from a CT of the lungs corresponds to 60-80 rem!

A PET total body emits 180-320 rem and a dosage of 7.5-10 Sievert (750-1000 rem) on the total body is lethal!

It must be stressed that immediate consequeces after little dosages of these radiations cannot be observed in human body even if Doses of radiation such as those given in radiation therapy can cause side effects. Short-term side effects depend on the area being treated but often include skin changes (ranging from mild reddening to something like a severe burn), nausea, vomiting, diarrhea, and low blood cell counts. There is also a risk of long-term side effects, which again vary depending on the area 
being treated. For example, radiation to the head and neck area can lead to problems with dry mouth and trouble swallowing.

\section{MATERIALS AND METHODS}

The AA have chosen to make their experimentations near a nuclear power plant in South Italy, exactly at Garigliano Centrale nucleare del Garigliano, Campania.

The nuclear reactor was stopped in 1978 for administrative problems and definitively decommissioned and abandoned in 1982.Presently 2200 squared meters of radioactive waste are stowed in the structure.

Ten volunteers have decided to undergo to the AA's experimentations, applying the aforesaid cosmetic formula on their neck and face for ten days twice a day.

The experimentations lasted ten days and the only way to state the health state of the volunteer each evening (after the sunset) was to let them to answer to a questionnaire concerning the difficulty of swallowing and the dryness of the mouth.

For this purpose, the questions kept on account a score (from 0 till 10) indicating the gravity of the symptoms.

O stands for perfect wetting of the mouth and optimal deglutition, while 10 signifies severe dryness of the mouth and difficulty of swallowing.

\section{RESULTS}

All the volunteers responded to the questionnaire indicating an average of scores oscillating from 6 to 7 , before the treatment, using the cosmetic lotion.

After ten days almost all the volunteers declared values of 1-3 as far as the deglutition was concerned (Daniel's test) and confirmed not to feel sensation of dry mouth.

\section{Consent}

The examination of the patient was conducted according to the Declaration of Helsinki principles.

\section{REFERENCES}

1. Andino JM. Chlorofluorocarbons (CFCs) are heavier than air, so how do scientists suppose that these chemicals reach the altitude of the ozone layer to adversely affect it?. Scien Am. 1999;264:68.

2. Part III. The science of the ozone hole. Retrieved March 5, 2007.

3. The antarctic ozone hole will recover. NASA. June 4, 2015. Retrieved August 5, 2017.

4. "Stratospheric ozone depletion by chlorofluorocarbons (Nobel lecture) - encyclopedia of earth". Eoearth.org. Archived from the original on September 9, 2011.

5. Scientific assessment of ozone depletion 2010, National Oceanic \& Atmospheric Administration.

6. Rothkamm K, Löbrich M. Evidence for a lack of DNA doublestrand break repair in human cells exposed to very low $\mathrm{x}$-ray doses, in: Proceedings of the National Academy of Sciences of the United States of America. 2003;100:5057-62.

Copyright by Piotr Brzeziński, et al. This is an open-access article distributed under the terms of the Creative Commons Attribution License, which permits unrestricted use, distribution, and reproduction in any medium, provided the original author and source are credited.

Source of Support: Nil, Conflict of Interest: None declared. 